\title{
Patient-Centered Appointment Scheduling: a Call for Autonomy, Continuity, and Creativity
}

\author{
John C. Matulis, DO, MPH® and Rozalina McCoy, MD, MS
}

When making an appointment, patients are generally unaware of how much clinician time is available to address their concerns. Similarly, the primary care clinician is often unaware of what the patient expects to accomplish during the visit, leading to uncertainty about how much time they can allot to each sequentially appearing concern, and whether they can reasonably expect to address necessary preventive services and chronic disease management. Neither patient nor clinician expectations can be adequately managed through standardized scheduling templates, which assign a fixed appointment length based on a single stated reason for the visit. As such, standardized appointment scheduling may contribute to inefficient use of valuable face-to-face time, patient and clinician dissatisfaction, and low-value care. Herein, we suggest several potential mechanisms for improving the scheduling process, including (1) entrusting scheduling to the primary care team; (2) advance visit planning; (3) pro-active engagement of ancillary team members including behavioral health, nursing, social work, and pharmacy; and (4) application of innovative, technologically advanced solutions such as telehealth and artificial intelligence to the scheduling process. These changes have the potential to improve efficiency, patient and clinician satisfaction, and health outcomes, while decreasing low-value testing and return visits for unaddressed concerns.

KEY WORDS: primary healthcare; appointments and schedules; healthcare quality; professional autonomy; call center.

\section{Abbreviations \\ EHR}

Electronic health record

$\mathrm{J}$ Gen Intern Med 36(2):511-4

DOI: $10.1007 / \mathrm{s} 11606-020-06058-9$

(c) Society of General Internal Medicine 2020

\begin{abstract}
"Those three things - autonomy, complexity, and a connection between effort and reward - are, most people will agree, the three qualities that work has to have if it is to be satisfying" Malcolm Gladwell
\end{abstract}

Marie's asthma was flaring. She was long overdue for depression follow-up, needed multiple medications renewed, and craved relief from her nagging knee pain. Full-time work and child-care responsibilities, limited parking, and inconvenient hours made getting to the clinic, at best a difficult task, feel impossible when she wasn't feeling well. When Marie called the clinic hoping to see her physician, she was told by the triage nurse that she could not see Dr. Smith, her primary care doctor within the recommended time frame, but should instead come in today to see another physician she had never met.

At the clinic, a young physician introduced himself $20 \mathrm{~min}$ after the scheduled appointment time. He swiftly asked questions about her breathing, formulated a treatment plan, and entered electronic orders. Marie, anxious about bringing up her other concerns, gingerly asked for medication renewals and mentioned her knee pain. As the physician glanced at his watch, she felt a pang of guilt, knowing she was causing him to fall further behind. He spent a few minutes looking through her chart, did a cursory exam, and suggested physical therapy - something she had been already doing without benefit. With a defeated look, the physician ordered an orthopedic consult and then struggled to find, verify, and renew her medications. Thirty-five minutes into their scheduled appointment, Marie could not bring herself to ask what she could do about her depression.

This case, in which important patient concerns are unable to be addressed, exemplifies many frustrations shared by patients, caregivers, and practicing primary care clinicians. The inability to address important items on the patient's and clinicians' lists has in the past been attributed to "overfull patient agendas"1, 2 and differing perceptions of the time actually available. ${ }^{3}$ For nearly 40 years, experts have recommended clinicians try to better meet patient needs through shared agenda setting, ${ }^{4-6}$ yet application of this approach remains limited. ${ }^{7}$ We submit that a central contributor to sub-optimal appointment experiences, such as Marie's, is the routinized scheduling process which does not reflect the needs of the individual patient.

\section{SHARED AGENDA SETTING IS NOT ENOUGH}

Even if applied broadly, shared agenda setting alone is inadequate to meet the needs of medically complex

Received February 17, 2020

Accepted July 13, 2020

Published online September 3, 2020 
patients, those with mental health concerns, or those who require care coordination. In settings with limited or variable in-office ancillary staff support, even a 20-min appointment - of which at least a few minutes are spent building rapport, eliciting the chief complaints, and setting the agenda-will not allow adequate time to manage multiple acute and chronic issues, deliver preventive care, and coordinate complex care needs. This is particularly true when the patient has not previously met the clinician, as rapport building takes longer and the clinician is not familiar with the patient's history and social circumstances. As the average Internal Medicine patient will present with three concerns,${ }^{8}$ basing the time allotted on a single concern without considering chronic disease management, and preventive service delivery, lacks face validity as an effective method of allocating clinician time.

\section{THE STATUS QUO: WHAT HAPPENS WHEN A PATIENT ASKS FOR AN APPOINTMENT?}

In smaller primary care practices, patients calling in with a concern may be connected directly to the clinician's nurse. This nurse, working closely with the clinician and often knowing the patient, would make a determination on how to best meet the patient's needs, whether an appointment is necessary, when it should be scheduled, for how long, and where it should be placed in the clinician's schedule. In that small, de-centralized primary care practice, any concerns about the scheduling decision could be reconciled through direct communication between the nurse and clinician.

In contrast, within large healthcare organizations, appointment triage may occur at a centralized location, ${ }^{9}, 10$ disconnected from the primary care team which knows the patient. Triage staff may follow scripted protocols to assess symptom severity and urgency, and determine if, when, and for how long the patient should be seen, using a standardized template to allot a fixed amount of time based on the stated concern, potentially scheduling the patient with any available clinician within the recommended time frame. This fragmentation of the visit scheduling process limits the opportunity for bi-directional communication between the scheduler and the primary care team and leaves the primary care team with limited capacity to modify scheduling to better meet the patients' needs.

In addition, patient's expectations of what can and will be covered during the appointment may vary, particularly as patients may not communicate the totality of their needs to the triage and scheduling teams with whom they have no established relationship. Patients may be preparing for their appointment by creating lists of items they would like addressed. This information is invaluable, particularly for clinically complex patients with multiple health needs or where caregivers may contribute to agenda setting. However, if neither the scheduler nor clinician is aware of the patient's "need to do" list before stepping into the room, important concerns will be inadequately addressed, cause the clinician to fall behind schedule, or both.

\section{POTENTIAL IMPACTS OF CURRENT SCHEDULING PRACTICES ON PATIENT EXPERIENCE, CLINICIAN BURN-OUT, AND DOWN-STREAM UTILIZATION}

Completing a "routine" appointment in primary care is becoming more difficult. Increasing medical and psychosocial complexity, mounting numbers of recommended preventive services and quality measures, an expanding and evolving evidence base for disease management, shared decision-making, electronic health record (EHR) hurdles, and administrative tasks all stretch visit time thin. As such, the work-load of primary care clinicians is under close scrutiny. ${ }^{1-13}$ Given concerns related on the quality of care and effects on clinician burn-out, there have been formal calls to end the brief duration (15 or $20 \mathrm{~min}$ ) appointment for medically complex primary care patients. ${ }^{13}$

Table 1 Commonly used Primary Care scheduling Templates

\begin{tabular}{|c|c|c|c|}
\hline Scheduling approach & Brief description & Advantages & Disadvantages \\
\hline $\begin{array}{l}\text { Stream scheduling } 1,26 \text {, } \\
15,27,28,29,30\end{array}$ & $\begin{array}{l}\text { Fixed blocks of time are allocated for } \\
\text { different visit types. A mixture of pre- } \\
\text { scheduled and acute visit slots are avail- } \\
\text { able }\end{array}$ & $\begin{array}{l}\text { Predictable, steady stream } \\
\text { of patients }\end{array}$ & $\begin{array}{l}\text { Acute care access may be limited, } \\
\text { does not account for rooming } \\
\text { inefficiencies and late arrivals }\end{array}$ \\
\hline Wave scheduling ${ }^{14,15}$ & $\begin{array}{l}\text { Several patients are scheduled at the same } \\
\text { time at the top of each hour and seen as } \\
\text { they arrive with catch up time available at } \\
\text { the } \\
\text { end of the hour }\end{array}$ & $\begin{array}{l}\text { Reduces inefficiencies created } \\
\text { by late patient arrivals, rooming } \\
\text { variation, and no-shows }\end{array}$ & $\begin{array}{l}\text { Unpredictable patient flows, } \\
\text { patients may be dissatisfied } \\
\text { with waiting }\end{array}$ \\
\hline Advanced access $* 4,5$ & $\begin{array}{l}\text { Patient is automatically granted any } \\
\text { appointment type within } 24 \mathrm{~h} \text { of request }\end{array}$ & $\begin{array}{l}\text { Improved patient access and } \\
\text { experience, lower rate of no- } \\
\text { shows }\end{array}$ & $\begin{array}{l}\text { Difficult to implement, potential for } \\
\text { mismatch between demand and available } \\
\text { staffing }\end{array}$ \\
\hline Open hours ${ }^{6}$ & Patients are seen in the order they arrive & $\begin{array}{l}\text { Simple, allows more time with } \\
\text { patients if needed }\end{array}$ & $\begin{array}{l}\text { Patient access and experience varies with } \\
\text { demand }\end{array}$ \\
\hline Cluster scheduling $^{7}$ & $\begin{array}{l}\text { Similar appointment types seen in same } \\
\text { half or full day }\end{array}$ & $\begin{array}{l}\text { Allows for resource/staffing } \\
\text { efficiencies, predictability }\end{array}$ & Does not address acute access needs \\
\hline
\end{tabular}

*Also includes open access, same day access scheduling schemes 


\section{A NEW CONCEPTUAL FRAMEWORK FOR OPTIMIZED PATIENT SCHEDULING}

In Table 1, we describe several commonly employed templates used in primary care scheduling. There are no guidelines or best practices for patient appointment lengths ${ }^{16}$ and there can, and should, be variation in scheduling templates across different settings, populations, and care delivery models. Appointment scheduling should be sufficiently flexible to accommodate the needs of the populations served and the resources available to the clinicians serving them. This flexibility, dependent on accurate recognition of patient needs and matching those needs to the primary care team's resources and work-flow, is a significant challenge.

Recognizing that patient needs are simultaneously complex and individual, a new conceptual framework is needed to allocate the valuable resource of primary care clinician time and expertise. This framework must capitalize on the longitudinal relationship between the primary care clinician, their team, and the patient, which has been established as foundational in delivering high-quality primary care. ${ }^{17-19}$ As the primary care team is ultimately responsible for how visit time is utilized, that team should be empowered to decide when, how, and with whom patients are scheduled in order to optimally align patient needs, the expertise of each care team member, and available resources. Giving the primary care team a sense of control over their calendar may have the added benefit of improving autonomy, the lack of which has been identified as a significant contributor to burn-out. ${ }^{20}$

Clinicians can successfully address patients' concerns in shorter periods of time if they are effectively supported by integrated clinical (e.g., nursing, social work, mental health, pharmacy) and non-clinical (e.g., scribes, secretarial) supports . Team-based care can be even more effective if planned and organized ahead of the visit to ensure that patients see needed care team members in the right sequence such as medication reconciliation, wound care, social services, and education.

Pre-visit planning is a promising approach to addressing overfull agendas, rushed office visits, and unmet patient needs ${ }^{21-23}$ and can facilitate flexible and efficient appointment planning. After an appointment is scheduled, questionnaires related to demographic and insurance information, symptom burden of specific conditions, and general review of systems may be issued prior to the appointment. ${ }^{22}$ Currently, the value added by gathering patient-provided information when not initiated by the care team is uncertain. However, if primary care teams were empowered to schedule their patients, they could use pre-visit planning more effectively for all appointment requests, whether planned or acute. Moreover, if patients and clinical teams both engage in pre-visit planning, a shared agenda can be developed. This would allow prioritization of patient needs, chronic disease management, and preventive service delivery. For example, a patient with hypertension and diabetes presenting with an upper respiratory tract infection could first see the nurse for vaccination and education on diabetes management, the pharmacist for insulin dose adjustment, and the social worker to address medication costs.

Adding another task to the primary care team will feel daunting. The question "where will the time and resources come from?" would be immediate. The answer will need to be creative, developed iteratively, and leverage the expertise of all involved team members and clinic leadership. Resources from other parts of the practice, including personnel no longer tasked with centralized primary care scheduling, may be able to perform tasks not requiring primary care team input such as preparation of medication refills, prior authorizations, and durable medical equipment requests. New scheduling models need to be thoughtfully developed, piloted, and iteratively refined based on local practice needs. Program implementation would need to be evaluated with respect to operational (i.e., access and fill rate indicators), clinical (patient health outcomes, receipt of recommended preventive services), and satisfaction (patient, staff) outcomes. Comparison of different scheduling approaches and correlating scheduling approach with outcomes important to patients and organizations are needed to better guide practices on selecting or modifying the scheduling approach chosen.

Technology can help drive innovation in care delivery and appointment scheduling. Artificial intelligence and machine learning methods, in which algorithms based on neural networks and large data sets can learn the most appropriate management decisions, ${ }^{24}$ may have particular value in patient scheduling, as these algorithms would have the capacity to incorporate data on social determinants of health, prior patterns of utilization, and documentation. ${ }^{25}$ Telehealth, particularly given the acceleration of its use in the era of COVID- $19,{ }^{26}$ is an important innovation in primary care delivery; understanding optimal application of this tool in both pre-visit planning and appointment scheduling will be an important future challenge. Organizations and funders should support research that explores the application of these types of innovative discoveries into every-day clinical practice.

\section{POTENTIAL IMPACT}

Let us re-imagine Marie's case. Her appointment, scheduled by a primary care team member who had previously worked with her and was aware of her issues with depression and knee pain, recognizes she should see her primary care physician and that several issues should be addressed in a longer appointment slot. Preparation for that visit, communicated to Dr. Smith, include brief, shared agenda setting, completion of necessary asthma and depression monitoring, and orders placed for an x-ray of her knee and an overdue pneumonia vaccine, the latter a quality improvement priority for the practice. Dr. Smith, having reviewed the relevant pre-visit planning information before going into the room, is confident and able to address all of the items on the shared agenda in the 
time the team deemed appropriate. The same team member returns at the end of the visit to coordinate Marie's follow-up care.

The frustrations, inefficiencies, and harms of inadequate primary care appointment scheduling are familiar to clinicians and patients. Re-imagining patient scheduling to center around the longitudinal primary care relationship is reinvigorating in several ways. First, it would allow the primary team to be more closely connected to patients, deepening existing relationships while using relevant information known to the team to better coordinate patient care. Second, it can afford the clinician and the primary team autonomy over the tempo, timing, and distribution of work during a busy clinic day. This autonomy would allow primary care teams to work more creatively, expand their base of resources, and function more effectively. Most importantly, this new conceptual framework could reinstate the patient's voice in their care to better meet their needs, improve patient and clinician experience, and close quality gaps important to both the patient and the healthcare system.

Corresponding Author: John C. Matulis, DO, MPH; Division of Community Internal Medicine, Department of Medicine, Mayo Clinic, 200 1st ST SW, Rochester, MN 55905, USA (e-mail: Matulis. John@mayo.edu).

Authors' Contribution John C. Matulis: Dr. Matulis is a Consultant and Assistant Professor of Medicine at Mayo Clinic in Rochester, MN. He was involved in the planning, conceptualization, and design of the article and drafted, revised, and finalized the current manuscript. The patient vignette is fictitious, based on a discussion with a family friend, discussions with numerous patients in his practice, and his own personal experience.

Rozalina McCoy: Dr. McCoy is a Consultant at Mayo Clinic and an Associate Professor of Medicine. She conceptualized and planned the project with Dr. Matulis. She assisted with planning, organization, writing, and finalization of the manuscript. She reviewed and revised all sections of the manuscript, and approved the final manuscript as submitted.

\section{Compliance with Ethical Standards:}

Conflict of Interest: Dr. McCoy reports grants from NIDDK and from AARP relevant to her work in Diabetes research, but outside the scope of the submitted work.

\section{REFERENCES}

1. Sinsky CA, Willard-Grace R, Schutzbank AM et al. In search of joy in practice: a report of 23 high-functioning primary care practices. Ann Fam Med 2013;11(3):272-8.

2. Marvel MK, Epstein RM, Flowers $\mathbf{K}$, et al. Soliciting the patient's agenda: Have we improved? JAMA 1999;281(3):283-7.

3. Beckman HB, Frankel RM. The effect of physician behavior on the collection of data. Ann Intern Med 1984;101(5):692-6.

4. Stewart M, Brown $\mathbf{J}$, Levenstein $\mathbf{J}$ et al. The patient-centred clinical method. Changes in residents' performance over two months of training. Fam Pract 1986;3(3):164-7.

5. White J, Levinson W, Roter $\mathbf{D}$. "Oh, by the way ...": the closing moments of the medical visit. J Gen Intern Med 1994;9(1):24-8.
6. Robinson JD, Tate A, Heritage J. Agenda-setting revisited: When and how do primary-care physicians solicit patients' additional concerns? Patient Educ Couns 2016;99(5):718-23.

7. Kaplan SH, Gandek B, Greenfield $\mathbf{S}$ et al. Patient and visit characteristics related to physicians' participatory decision-making style: Results from the Medical Outcomes Study. Med Care 1995:1176-87.

8. Brandenburg $\mathbf{L}$, Gabow $\mathbf{P}$, Steele $\mathbf{G}$, et al. Innovation and best practices in health care scheduling. NAM Perspect. 2015.

9. Rohleder T, Bailey B, Crum B et al. Improving a patient appointment call center at Mayo Clinic. Int $J$ Health Care Qual Assur 2013;26(8):714-28.

10. Arndt BG, Beasley JW, Watkinson MD et al. Tethered to the EHR: primary care physician workload assessment using EHR event log data and time-motion observations. Ann Fam Med 2017;15(5):419-26.

11. Erickson SM, Rockwern B, Koltov $\mathbf{M}$ et al. Putting patients first by reducing administrative tasks in health care: a position paper of the American College of Physicians. Ann Intern Med 2017;166(9):659-61.

12. Helfrich CD, Simonetti JA, Clinton WL et al. The association of teamspecific workload and staffing with odds of burnout among VA primary care team members. J Gen Intern Med 2017;32(7):760-6.

13. Linzer M, Bitton A, Tu S-P, et al. The end of the 15-20 minute primary care visit. J Gen Intern Med; 2015; 30 (11) 1584-1586.

14. McLaughlin DB, Olson JR. Healthcare operations management: Health Administration Press Chicago, IL; 2008.

15. Lehner V, Smith DS. Wave Scheduling: Efficient Precepting in the Outpatient Setting. J Physician Assist Educ 2016;27(4):200-2.

16. Institute for Healthcare Improvement T. Reduce Scheduling Complexity: The Insititute for Healthcare Improvement; 2019 [Available from: http:// www.ihi.org/resources/Pages/Changes/ReduceSchedulingComplexity. aspx.

17. Cabana MD, Jee SH. Does continuity of care improve patient outcomes. J Fam Pract 2004;53(12):974-80.

18. Van Walraven C, Oake N, Jennings A, Forster AJ. The association between continuity of care and outcomes: a systematic and critical review. J Eval Clin Pract 2010;16(5):947-56.

19. Shanafelt TD, Dyrbye LN, West CP. Addressing physician burnout: the way forward. JAMA 2017;317(9):901-2.

20. Haupert A Pre-Visit Planning: Save time and improve Care: American Medical Association and Society for General Internal Medicine; 2014 [Available from: https://edhub.ama-assn.org/steps-forward/module/ 2702514.

21. Sinsky CA, Sinsky TA, Rajcevich E. Putting pre-visit planning into practice. Fam Pract Manag 2015;22(6):34-8.

22. Vo MT, Uratsu CS, Estacio KR, Altschuler A, Kim E, Alexeeff SE, et al. Prompting Patients with Poorly Controlled Diabetes to Identify Visit Priorities Before Primary Care Visits: a Pragmatic Cluster Randomized Trial. J Gen Intern Med 2019;34(6):831-8.

23. Rajkomar A, Dean J, Kohane I. Machine learning in medicine. N Engl J Med 2019;380(14):1347-58.

24. Lin SY, Mahoney MR, Sinsky CA. Ten ways artificial intelligence will transform primary care. J Gen Intern Med 2019:1-5.

25. Hollander JE, Carr BG. Virtually perfect? Telemedicine for covid-19. N Engl J Med. 2020, 2020 epublished ahead of print.

26. LaGanga LR, Lawrence SR, editors. Appointment scheduling with overbooking to mitigate productivity loss from no-shows. Proceedings of Decision Sciences Institute Annual Conference, Phoenix, Arizona; 2007.

27. Rose KD, Ross JS, Horwitz LI. Advanced access scheduling outcomes: a systematic review. Arch Intern Med 2011;171(13):1150-9.

28. Murray M, Bodenheimer T, Rittenhouse $\mathbf{D}$ et al. Improving timely access to primary care: case studies of the advanced access model JAMA. 2003;289(8): 1042-6.

29. Turkcan A, Toscos T, Doebbeling BN, editors. Patient-centered appointment scheduling using agent-based simulation AMIA Annual Symposium Proceedings; 2014: American Medical Informatics Association.

30. Gupta D, Denton B. Appointment scheduling in health care: Challenges and opportunities. IIE Trans 2008;40(9):800-19.

Publisher's Note: Springer Nature remains neutral with regard to jurisdictional claims in published maps and institutional affiliations. 